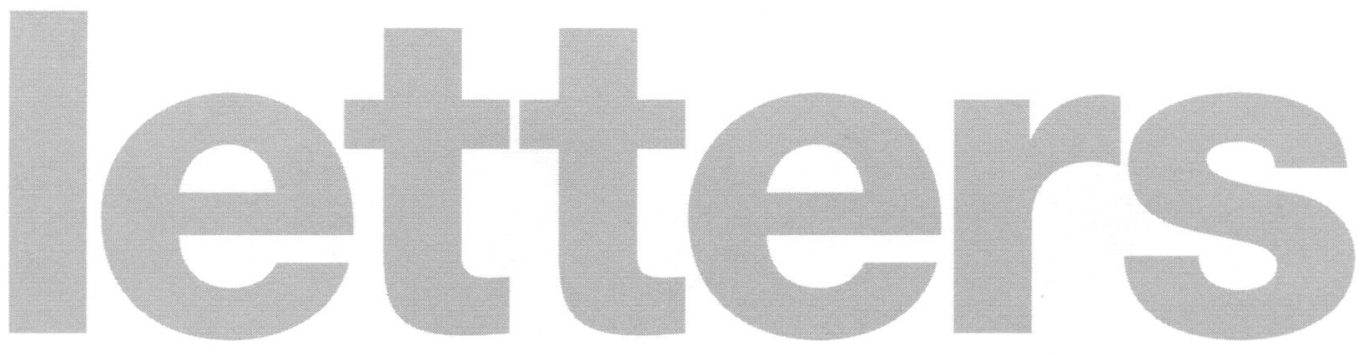

\section{Engineering judgement}

Sir: Reading Sam Price's paper on cantilevered staircases (arq vol.1: no.3) was almost as delightful as hearing him present an earlier version at the Institution of Structural Engineers History Group a couple of years ago He leaves us with the perception that there are three or four analytical models which can describe how these stairs work and various degrees of purity of application for each, but most examples are a blend and difficult to understand.

Herein lies a problem which goes back to structural engineering education. We are taught to calculate and calculations require simple mathematical models. Blending mathematical models is difficult and to be avoided. When we do there is usually an assumption based on engineering judgement.

But our engineering judgement is cultivated on mathematical analysis rather than practice. This leaves us with a very hollow feeling that is only concealed by generous applications of factors of safety. Practice, on the other hand, makes us feel robust - you build one and it works so you are very confident about building another simple! So it was with the builders of these staircases and I am quite sure they understood what they were doing better than we do with our analysis and safety factors. They experienced the limits - we make calculated guesses at them.

The staircase by Arups at Channel 4 (Figs. 33 and 36) eloquently makes the point. Arups appear to have taken one of Sam's theories and made a staircase out of it, amenable to analysis and using calculable materials and of course, factors of safety. Previous engineers would have relied on judgement (implying a blend of theories), craftsmanship and quite probably a live load test along the way or on completion.

So how can we make our engineers more robust in their judgement? We should let them rely less on mathematical analysis (while not neglecting the fundamentals) and exercise them more in engineering logic and proportion. Let them have ideas, test them to failure and then analyse the failure.

Nineteenth-century engineers built a great deal at a young age with more judgement than analysis. Today, we need to break out from under the weight of mathematics. Thanks, Sam, for posing the problems and putting forward believable theories and no mathematics - other than reassuring us that you had done some.

\section{Bryn Bird}

London

Bryn Bird, an engineer, is a partner in Whitby and Bird

\section{Barcelona experience}

Sir: The photograph (above) is of a staircase which we have been using for over 30 years based on the so called cantlevered staircase mentioned in Sam Price's paper (arq vol.1: no.3). Being unable to calculate it, we used reinforced reconstructed stone and tested it on site till collapse. It passed all the safety inspections. It is not cantilevered, being bedded $15 \mathrm{~cm}$ in the lateral wall, but once the constructor left out the piece connecting the treads at the bottom of the staircase and it stayed up. So we assume the weight is transferred from step to step but also together with a diagonal thrust (it was a circular staircase). The maximum tread width we have built is $1.80 \mathrm{~m}$ for a school.

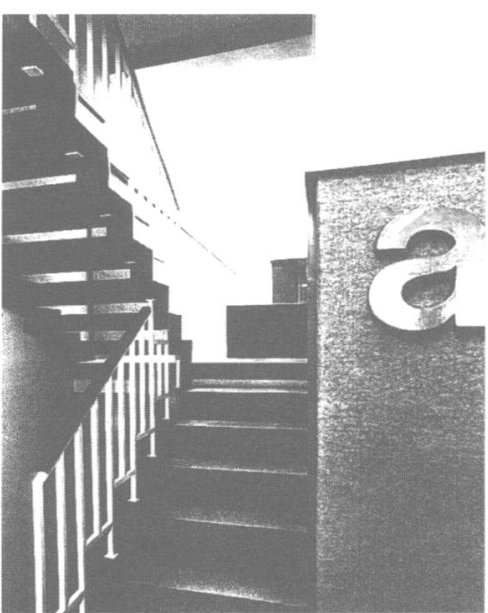

MBM's staircase. See 'Barcelona experience'

For some reason or other we call it the 'gothic' staircase, perhaps because we observed its earliest use in castles, but the inspiration comes directly from the London Georgian houses, also referred to in Price's paper.

Anyway, it just goes to show that arq makes fascinating reading. David Mackay

Barcelona

David Mackay is a partner in MBM

Architects. See pp.28-37 of this issue

\section{Behaviour and geometry}

Sir: William Fawcett's paper, 'Architecture: functional approach or the case for user research' (arq vol.l: no.3), structured around five topics which introduce elements of user research, is rich in example and insight. However, I found the overall conceptual structure confusing and unsatisfactory. This I believe lies in his opposition of 'geometry' and 'behaviour' and the argument that for satisfactory architectural design we somehow need to bring these into balance in the architect's consciousness. Collectively architects 
do seem to have an unenviable track record in satisfying users and the suspicion of a predilection for geometry and little else is possibly not wholly unfounded. If behaviour and geometry can be opposed, itself a questionable concept, then I believe that the problem for design and research is not simply a matter of relative quantity of these elements but of the relationship between the two.

For me, the first topic is the most problematic. It illustrates the point that random processes often display a level of order in aggregate. It is well known that if we throw two unbiased dice and add their numbers together there is a higher probability of achieving the value 7 than any of the other possible values (2 to 12). The value 7 is six times more likely than the value 2 . The problem is that, if you only have one throw, even backing 7 is a very long shot. I think I know what he is driving at but his example misses the point. What is really important is where knowledge intervenes to reduce randomness and shows that there are in fact reasonably stable relationships between say the formation of populations and the way that they occupy buildings. It is typological knowledge which makes design possible even in speculative situations.

The second topic, the capacity of educational buildings, is one of very current interest at DEGW. Fawcett identifies three factors which affect utilisation: the stock of buildings (space), the curriculum (activities) and activity-space management. Following the lead provided by that brilliant research team at LUBFS in Cambridge in the 1960-70s, we refer to the first two as supply and demand and the design task is to balance these by managing either supply or demand or both. A recent study for the University of Cambridge asked us to consider both sides of this equation in the context of an existing Arts Faculty building. When we measured space use over time we discovered some interesting patterns. Seminar rooms did achieve $80 \%$ utilisation during the periods of peak demand (in the mornings) and so, even if this old DES yardstick is arbitrary, it is not intrinsically unachievable. It will be no surprise, in a collegiate environment, that this figure was not sustained over the teaching week and, of course, measured over the academic or especially the calendar year, utilisation of these spaces is extremely low. We aiso found that the overall pattern of use of libraries and academic offices followed that of teaching space. Again this is not surprising in the collegiate context where the centre of activity moves from faculty to college in the afternoon. Demand in the academic environment is particularly uneven and so makes high utilisation of space extremely problematic. One of the challenges in higher education is to what extent the pattern of demand (either within or from outside) can be modified to provide a better fit (in use) to the expensive resources occupied. The office world is being revolutionised by the discovery, from user research, that new patterns of work mean that traditional formulae for the provision of office space which gave everyone a permanent workplace are no longer relevant. At the level of the individual user, our data also showed a range of patterns of use of academic offices which reflect to some degree different roles within the university. For some the office is 'home' for the whole working day (except when lecturing), the place for tutorials, preparation study and research and, for others, not much more than an e-mail terminal. It is this type of data which has allowed us to have a creative dialogue with users. We have been able to show that the stock of space (supply) can be increased by physical design but that extending the capacity is also about innovation in use which changes the demand.

Fawcett's concept that capacity is reduced by restrictions which come from specialisation (which inevitably precludes some activity), timetabling (where people cannot be in two places at the same time) and time constraints (where activity is limited to particular times of the day or week) is elegant. However, I am not convinced that it tells us much if these elements are subsumed in a general model of use indices. The key is surely to understand the different way in which these elements can enter into the devising of intelligent design solutions. Perhaps not all design solutions are geometrical.

His final topic, the brief, finds the opposition of behaviour and geometry at its most problematic. Shortage of space prevents me from commenting in detail but it should also be noted that the concept of the brief as the 'institutionalised interface between users and designers' is outdated. Briefing is increasingly seen as a creative, iterative process conducted between the two rather than a one-off statement of intent or content.

As Fawcett argues we need more user research as well as more architects who actually believe users and not just their peer group matter. The knowledge which reduces the gap is about the relationship of social and spatial organisation. The design process that supports its closure is 
one where briefing is investigative and dynamic with the user as both subject and participant.

Michael Bedford

London

Michael Bedford is a director of DEGW

\section{Working with nature}

Sir: Dennis Ho's paper on climatically responsive atrium design (arq vol.1: no.3) reveals a very useful piece of work, though inevitably the article compresses the information drastically. When I wrote Atrium Buildings, development and design (Architectural Press/Butterworths 1983 and '86), I attempted to set down a climatically responsive discipline for design but without the modelling resources now available. Most of my intuitive guidelines seem to be confirmed by the modelling, but Ho's differentiation of climatic zones is very helpful in refining understanding.

Ho concentrates on comfort in the atrium space itself rather than on the whole building where the costs and benefits have to be measured. In the UK over the past five years a generic pattern has emerged of two parallel occupied spaces on an east-west axis enclosing a Linear or Centralised atrium in Ho's terms. The north-south orientation of the occupied space optimises their comfort while, apparently, being suboptimal for atrium comfort. It is also very noticeable that taller spaces (five or six levels) work better than lower (two or three levels) in driving natural ventilation.

$\mathrm{Ho}$ and I are similarly interested in varying the glazing of walls between atria and occupied space to control solar gain and recognise varying daylight availability. I would add that having good, reflective walls at the top of tall atria does greatly improve light transmission to lower levels and thus the overall performance of the building

It would be good to see Ho's work expanded in length so that it would be a real source for designers. The present compression makes it often ambiguous or unclear. Incidentally, while Atrium Buildings is now out of print, I still hold a stock to meet occasional needs.

Richard Saxon

London

Richard Saxon, an architect, is chairman of Building Design Partnership, 16 Gresse Street, London W1A 4WD

\section{Hill House corrections}

Sir: The purpose of this letter is to point out a few errors in my paper on the symbolic geometry of $C$. R. Mackintosh's Hill House (arq vol.1: no.3) and to enlighten readers about footnote 16 .

Two figures (15 and 20) lost letters ' $X$ ' and ' $C B L$ ' respectively. I hope that the text and captions allowed readers to locate them. On p.59, 'Fig. 19c' should have read 'Fig. 19d', and vice versa. The caption to Fig. 26 should have read: 'Relations between goldensection rectangles $A D$ and $D Y$, and between root-five rectangles $A O$ and BY highlight ...' The corresponding paragraph on p.60 also used the wrong letters to refer to the figure. ' $L C$ ' should be replaced by ' $Q D$ '; 'CE' by 'DF'; 'BC' by 'AD'; 'CX' by 'DY'; 'BO' by ' $A O$ '; and ' $A X$ ' by ' $B Y$ '.

Footnote 16 refers to the analysis of the washstand illustrated in Fig. 16. The analysis was based upon a colour photograph of the washstand published in R. Billcliffe, Charles Rennie Mackintosh: The Complete Furniture, Furniture Drawings \& Interior Designs, first published 1979 and reissued three times since, in 1980 1986 and 1989. The photograph differs significantly from the washstand now on show at The Hill House: the flower appears not to be filled with mirror-glass and the 'flower-ovary' appears as a dark, curved form located within the $3 \times 5$ golden-section [Fig. 16d]. Enquiries made while researching the article produced no explanation for this unique plate. Given its importance in the catalogue, in an original footnote 16 , I wondered whether the washstand had been restored since the photograph was taken: perhaps the flower-mirror, which makes functional and symbolic sense, since it reflects the rose-head of the Rose-Lady, had been replaced while the curved form had been erased. The solution to the mystery came too late for the press, although there was time to amend footnote 16 . It seems that the dark form in the colour-plate is the hood of a camera lens! I am grateful to Anne Ellis, Curator of The Hill House, for tracking down the photographer and establishing the truth. Although the discovery necessarily changes the explanation of the washstand at this point, the essential meaning remains the same, as indicated in the published footnote 16

The new explanation involves looking still more carefully at the stylised flower and seeing in it two possible interpretations. The first reading evokes the external form of the flower: a thick stalk (a square of green, ribbed leaded glass at the base of the figure) terminating in an ovary (the $3 \times 5$ golden-section of mirrorglass) at the base of the corolla (also in mirror-glass and edged with four oval segments of pink glass). The second reading evokes the internal structure of the flower: a group of three verticals on either side of the $3 \times 5$ mirror-plane, each representing a style rising from the green square, now an ovary, and terminating in an oval segment of pink glass, the stigma. The abnormal presence of two stigmata is highlighted by the discovery of the cruciform (Fig. 16c) and leads to the identification of the stylised flower with the diagram of the human female reproductive system, and of the flower-ovary at the base of the corolla (the $3 \times 5$ golden-section rectangle) with the vagina (Fig. 16d).

An off-print with amended text and captions to take account of the above errata has been produced to coincide with the Charles Rennie Mackintosh retrospective exhibition, which opened to the public 24 May at the McLellan Galleries, Glasgow. After 30

September, the exhibition travels to the Metropolitan Museum, New York (21 November 1996 to 16 February 1997), to The Art Institute of Chicago (29 March to 22 June 1997), and to the Los Angeles County Museum of Art (3 August to 12 October 1997). Eleanor Gregh, Glasgow

Eleanor Gregh is a lecturer at the University of Glasgow

Letters, should be typed doublespaced and sent to Peter Carolin, Architectural Research Quarterly, c/o University of Cambridge Department of Architecture, 1 Scroope Terrace, Cambridge, CB2 1PX, faxed to $+44(0) 1223$ 332960 , or e-mailed to pc207@hermes.cam.ac.uk The editor reserves the right to shorten letters. 


\section{Why don't you submit your research paper to arq?}

\section{arq welcomes research papers on:}

- architectural, urban and landscape design

- building evaluation

- architectural history and theory

- environmental theory and design

- building materials, structure and building management

- information technology

- issues in architectural and interdisciplinary research, education and practice

Submissions from outside the United Kingdom are most welcome.

Those wishing to contribute may either:

- make a very brief written proposal (please include details of telephone and fax numbers)

- send an outline of the proposed paper

- submit a completed paper which should not normally be more than 5000 words long and should include copies of the relevant illustrations.

Papers which are written specifically for publication in arq should conform to the requirements given in the notes for contributors published inside the back cover of this issue.

A particular opportunity exists for academics and practitioners to act both as critics of competition projects, new buildings and environments in use. Architects and other designers who wish to submit their work for critical assessment or evaluation should write to the editor outlining (on not more than one side of an A4 sheet) the location, purpose and significance of the work and enclosing sufficient drawings and/ or photographs to illustrate its quality. Academics and practitioners wishing to act as critics or evaluators are invited to send the Editor a brief curriculum vitae together with a recent example of their writing.

The Editor and the Editorial Board regret that they are unable to enter into correspondence unless a submission is considered suitable for publication. Where a paper is rejected by the referees, the author will be informed of the referees' comments.

All proposals and submissions should be sent to the Editor:

Peter Carolin

arq (Architectural Research Quarterly)

c/o University of Cambridge Department of Architecture

1 Scroope Terrace

Cambridge CB2 1PX

England

Fax $+44(0) 1223332960$

\section{and subscribe at no risk}

Please sign me up immediately for an annual subscription to Architectural Research Quarterly covering 4 issues at the special launch rate of: (tick one box only)
Personal rate
$\square £ 70 £ 45$ (Europe)
$\square £ 85 £ 55$ (Rest of World)
Institutional rate
$\square £ 120 £ 89$ (Europe)
$\square £ 135 £ 99$ (Rest of World)
$\square \$ 110 \$ 70$ (Americas)

I enclose a cheque for $£ / \$$ payable to Emap Business Communications or charge $\Sigma / \$ \quad$ to my Visa, Access, MasterCard, Switch or AmEx

Account number

Expiry date _ _ Switch Issue Number ___ Signature

Title

Initial

Surname

Job Title

Organisation

Address

No-risk guarantee - I understand that, if for any reason I decide not to continue my subscription, I may cancel within 6 months (in writing) for a full no-questions refund. 